\title{
Usefulness and Limitation of Ultrasonography in the Diagnosis of Intestinal Intussusception in Cows
}

\author{
Sheikh Imran, S. P. Tyagi, Adarsh Kumar, Amit Kumar, Arvind Sharma, and Shivali Sharma \\ Department of Veterinary Surgery and Radiology, DGCN College of Veterinary and Animal Sciences, CSK HP Agricultural University, \\ Palampur, Himachal Pradesh, 176 062, India \\ Correspondence should be addressed to Sheikh Imran, sheikhimran_08@rediffmail.com
}

Received 22 September 2010; Revised 7 December 2010; Accepted 20 January 2011

Academic Editor: Tomoyuki Shibahara

Copyright (๑) 2011 Sheikh Imran et al. This is an open access article distributed under the Creative Commons Attribution License, which permits unrestricted use, distribution, and reproduction in any medium, provided the original work is properly cited.

The present study was conducted on 6 chronically ill Jersey/Red Sindhi cross-bred cows, which were suspected for intestinal obstruction on the basis of history and clinical signs. These cows were ultimately diagnosed with intestinal intussusception based on a combination of clinical, ultrasonographic and surgical examinations. "Bull's eye lesion" was the most prominent ultrasonographic finding, diagnostic for intussusception either trans-abdominally or transrectally. Dilated intestinal loops greater than $3.1 \mathrm{~cm}$ (mean $\pm \mathrm{SE}, 4.41 \pm 0.25$ ) were imaged in the lower flank and the 12th intercostal space on the right side. Ultrasonography proved to be a useful tool in supplementing and substantiating the transrectal findings in cases of the bovine intestinal intussusception. However, ultrasonography was not significantly helpful where transrectal examination of the cows did not reveal any suspected intestinal mass.

\section{Introduction}

Intussusception can be considered as a sign which is consequence of a gastrointestinal tract disease [1]. In its development, the orad portion of gut (intussusceptum) usually is engulfed and propelled distally by peristaltic action of an enveloping portion (intussuscipiens) [2]. Intussusception occurs sporadically in cattle of all ages, breeds, and gender and may be seen any time during the year [3]. Among the various causes of mechanical ileus, intussusception is an uncommon cause of intestinal obstruction in adult cattle [2]. Clinically, the patients are presented with a history of colic, anorexia, lethargy, and lack of defecation. Sex and season are not significantly associated with the cattle developing intussusception, whereas calves less than 2 months old are at greater risk of developing small intestinal intussusception than older cattle [3]. However, intussusception has been considered to be the most common cause of intestinal obstruction in Indian cross-bred hill cattle [4]. The prognosis for return to productivity after surgical correction of intussusception varies and depends upon duration of the lesion [5]. Although ultrasonography has been widely used as a diagnostic tool in bovine internal diseases there is limited ultrasonographic data describing intestinal intussusception in cattle [6-8]. The present study was undertaken to investigate the utility of ultrasonography in the diagnosis of intestinal intussusception in cattle.

\section{Materials and Methods}

Six cows with the history of cessation of defecation ranging from 3-8 days were presented. The initial signs of acute intestinal colic manifested by vigorous kicking at belly, paddling of limbs, tremors of muscles especially of hind quarters, shifting recumbency, and repeated attempts to void feces along with flatus were noticed by owners before referral to the teaching veterinary clinical complex, CSK HP Agricultural University, Palampur. The feces gradually turned scant with hard dung balls covered with mucous, and later it comprised only tarry viscid mucous. Other associated observations were anorexia and cessation of milk yield. All the affected animals were treated with intravenous dextrose normal saline, purgatives, and rumenotorics by referring veterinarians. Two pregnant cows of over 7-day duration of illness were recumbent at the time of presentation 


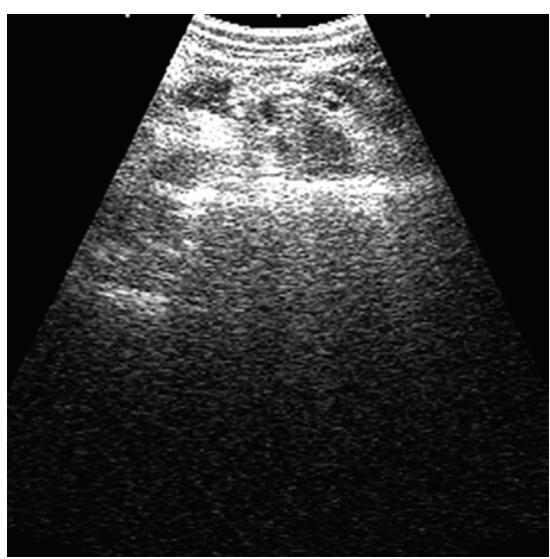

(a)

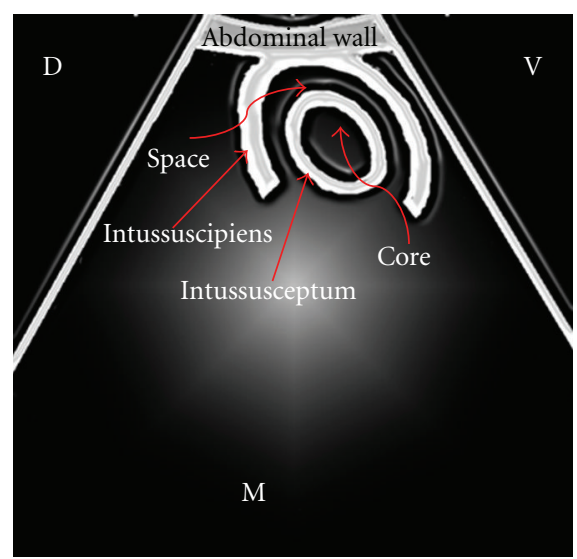

(b)

FIGURE 1: Ultrasonogram of jejunal intussusception imaged from ventral flank in cross-section. D: dorsal, V: ventral, M: medial.

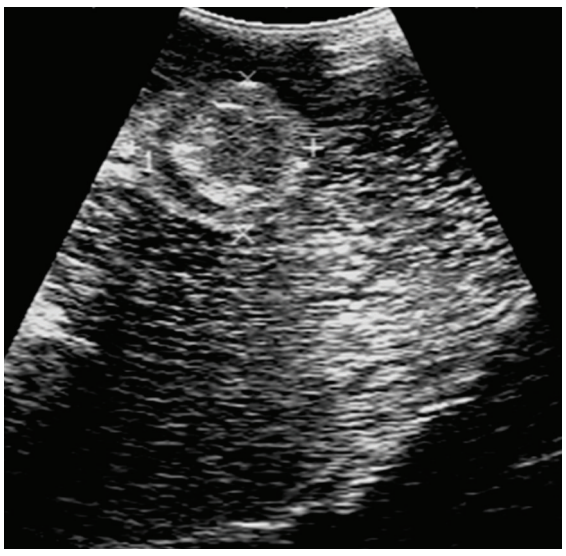

(a)

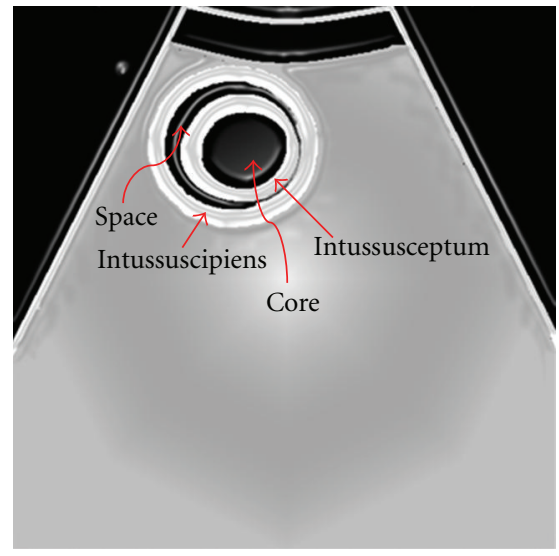

(b)

FIGURE 2: Ultrasonogram of jejunal intussusception imaged transrectum in cross-section.

and did not respond to manual assistance. All these cows were subjected to detailed clinical examination followed by ultrasonography and exploratory laparotomy. For transabdominal ultrasonography, the area extending from tuber coxae to 6th intercostal space and from dorsal midline to linea alba on right side was shaved. All animals except 2 recumbent pregnant cows were secured in standing position in a crate and the right hemiabdomen was examined with a $3.5 \mathrm{MHz}$ curvilinear transducer in a standard manner $[9,10]$. The pregnant cows were scanned in left lateral recumbency. In 1 case suspected, intestinal mass was scanned transrectally by using a $3.5 \mathrm{MHz}$ microconvex transducer after covering it with a gel laden polythene sleeve. The surgically resected portions of intussuscepted segments were subjected to water bath studies to correlate with the ultrasonographic findings in standing cows.

\section{Results}

Small intestinal intussusception was confirmed during ultrasonography and/or exploratory laparotomy in all these cows.
On clinical examination, the animals were generally dull and depressed with dry muzzles and sunken eyes. The rectal temperature was subnormal. The respiratory rate was often elevated with shallow respiration. The heart rate of the affected animals was found to be slightly elevated initially, but as the chronicity of the cases developed the heart rate increased considerably. Abdominal auscultation revealed mild tinkling and fluid splashing sounds of borborygmi in 3 cases and no sounds in rest of the 3 cows. Transrectal examination revealed absence of fecal material with dryness of rectal mucosa. Tentative diagnosis of the intestinal intussusception could be done by transrectal palpation in only 4 cows. In these cows, the obstructed portion was felt as a hard and thick impacted mass along with distended intestinal loops. The manipulation of this segment elicited severe pain response by cows characterized by tendency to lie down and groan. Transrectal examination could not reveal any palpable mass in the remaining 2 pregnant cows.

The hematological parameters revealed increased hematocrit along with elevated total leukocytic count and total erythrocytic count towards higher range. The laboratory 
TABLE 1: Preoperative clinical parameters in cases of intestinal intussusception in cows.

\begin{tabular}{|c|c|c|c|}
\hline Reference range values & $\begin{array}{l}\text { Clinical values } \\
(\text { Mean } \pm \text { SE })\end{array}$ & Reference range values & $\begin{array}{l}\text { Clinical values } \\
(\text { Mean } \pm \text { SE })\end{array}$ \\
\hline $\begin{array}{l}\text { Rectal temperature } \\
\left(101-102^{\circ} \mathrm{F}\right)\end{array}$ & $100.7 \pm 0.66$ & $\begin{array}{c}\text { Heart rate } \\
(60-80 \text { beats } / \mathrm{min})\end{array}$ & $83.33 \pm 2.46$ \\
\hline $\begin{array}{l}\text { Respiration rate } \\
(15-30 \text { breaths/min) }\end{array}$ & $25 \pm 1.69$ & Hematocrit (23-36\%) & $42 \pm 1.79$ \\
\hline $\begin{array}{l}\text { Hemoglobin } \\
(7.5-12.5 \mathrm{~g} / \mathrm{dL})\end{array}$ & $9.43 \pm 0.45$ & $\begin{array}{l}\text { Total leukocyte count }(4-20 \\
\left.\quad \times 10^{3} / \mu \mathrm{L}\right)\end{array}$ & $9.24 \pm 0.42$ \\
\hline $\begin{array}{l}\text { Total erythrocyte count } \\
\left(5-8 \times 10^{6} / \mu \mathrm{L}\right)\end{array}$ & $6.34 \pm 0.34$ & Lymphocytes (58\%) & $56.83 \pm 1.92$ \\
\hline Neutrophils (28\%) & $41.17 \pm 2.09$ & $\begin{array}{l}\text { Peritoneal fluid cell count } \\
\quad\left(1-20,000 \text { cells } / \mathrm{mm}^{3}\right)\end{array}$ & $3591.67 \pm 548.55$ \\
\hline $\begin{array}{l}\text { Peritoneal fluid proteins } \\
(1-5 \mathrm{mg} / \mathrm{dL})\end{array}$ & $5.17 \pm 0.50$ & $\begin{array}{l}\text { Ruminal fluid chloride } \\
(30 \mathrm{mEq} / \mathrm{L})\end{array}$ & $66.1 \pm 8.036$ \\
\hline
\end{tabular}

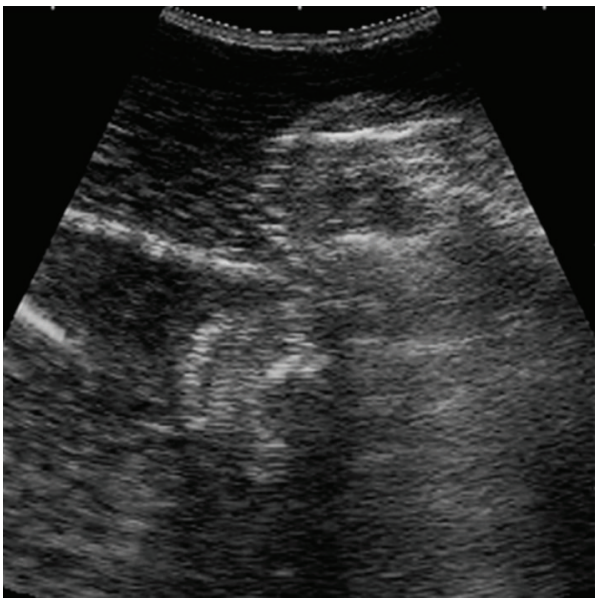

FIGURE 3: Ultrasonogram of a resected segment of jejunal intussusception in a water bath.

tests indicated a very high increase in ruminal fluid chloride concentration and protein and cellular content of visibly turbid peritoneal fluid (Table 1).

Intestinal intussusception was diagnosed with the help of ultrasonography in only 4 non-pregnant cows. The pattern of intussusception in cross-section resembled a multilayered mass of elliptical or circular rings with varying echogenicities. The intussuscipiens consisted of echogenic layers interspersed with hypoechogenic portions indicative of edema, whereas the intussusceptum was often echogenic/hypoechogenic with a hypo- to anechogenic core. The intussuscipiens and intussusceptum were separated by a hypo- to anechogenic space.

The cross-sectional patterns of the intestinal intussusception observed on ultrasonography of the standing cows, water bath study and frozen transverse section were similar (Figures 1, 2, 3, and 4). Optimal imaging of intussusception in longitudinal view was possible in only 2 cows even after thorough fanning of the ultrasound beam. Longitudinal scanning comprised of echogenic parallel lines separated by hypoechogenic lines with a hypo- to anechogenic core.

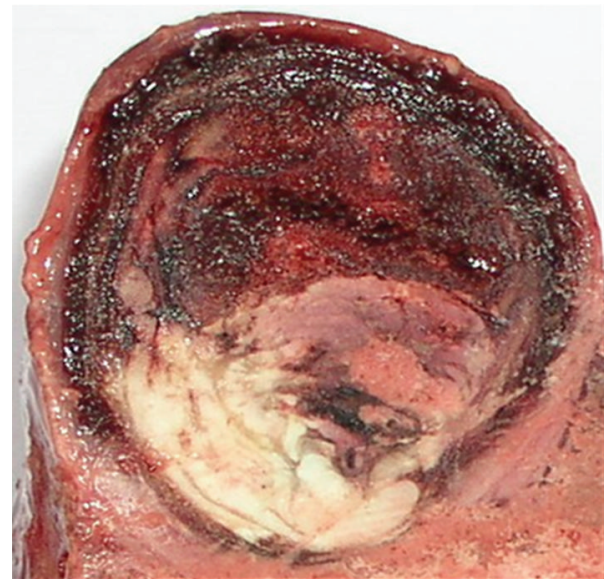

Figure 4: Frozen transverse section of an intussusception of jejunum.

In 2 cases, the ultrasonographic diagnoses were augmented by bringing the suspected intestinal segment towards the right abdominal wall by transrectal manipulation. The loops of the jejunum were observed both in transverse and sometimes longitudinal sections. Generally, the lumen of intestinal loops was dilated and static in all the cows (Figures 5 and 6). However, sometimes weak contractions of the intestinal wall manifested by recurrent changes in its luminal size were seen.

The largest diameter of dilated loops of jejunum ranged from 3.1 to $5.5 \mathrm{~cm}(4.41 \pm 0.25 \mathrm{~cm})$. The echogenicity of intestinal contents varied from hyper- to anechogenic, whereas the intestinal wall appeared echogenic. Swirling fluid contents due to respiratory movements along with acoustic shadowing of hyperechogenic feed particles were seen in all the cows. In 3 cows, anechogenic fluid between the intestinal loops was also seen.

The number of jejunal loops ranged from 10 to 12 in one scan at a depth of $12 \mathrm{~cm}$ in lower flank and 12th intercostal space in all cases. The number of intestinal loops always decreased when transducer was moved cranially up to 


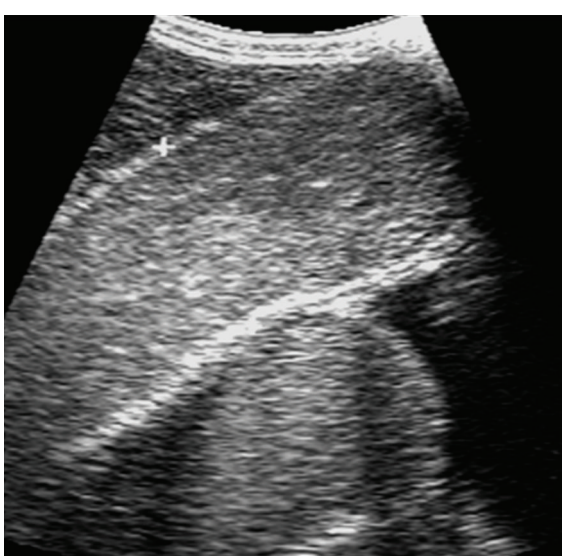

(a)

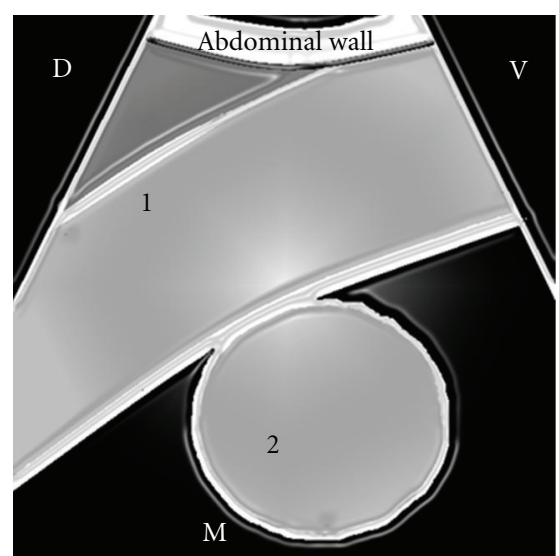

(b)

Figure 5: Ultrasonogram of dilated jejunal loops in jejunal intussusception imaged from ventral third of flank in longitudinal and crosssections. 1- Pre-intussusception dilated loop in longitudinal section with echogenic content, 2- Pre-intussusception dilated loop in crosssection with echogenic content, D: Dorsal, V: Ventral, M: Medial.

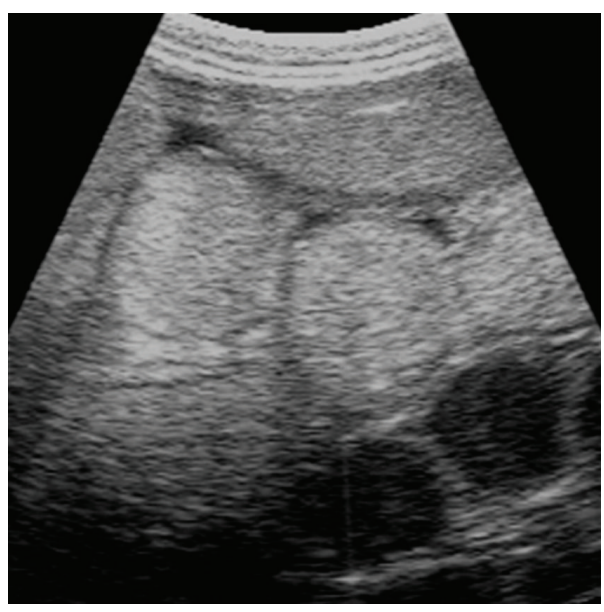

(a)

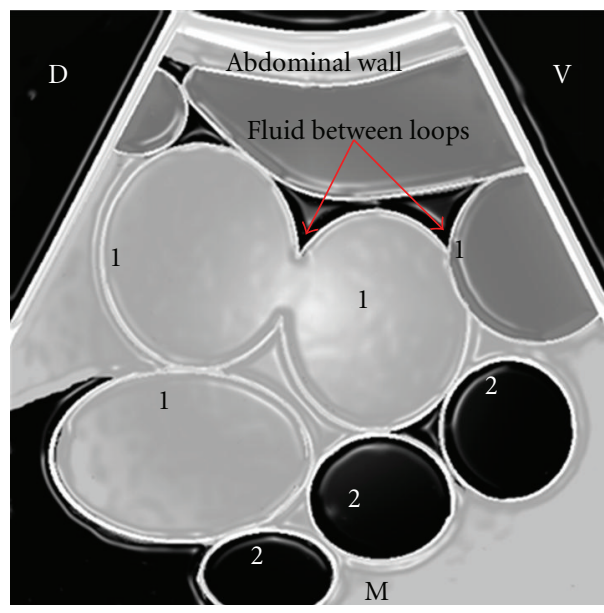

(b)

FIGURE 6: Ultrasonogram of dilated jejunal loops in jejunal intussusception imaged from mid-flank in cross-section. 1- Pre-intussusception dilated loops with echogenic content, 2- Post-intussusception loops with reduced diameter and anechogenic content, D: Dorsal, V: Ventral, M: Medial.

9th intercostal space. Further, postintussusception intestinal loops with reduced diameter and slight motility were also seen intermittently (Figure 6).

The rumen, omasum and abomasum were found to be markedly dilated extending beyond their normal topographic boundaries as established by a study conducted on 10 healthy Jersey/Red Sindhi cross-bred cows [10]. The omasal distension was primarily dorsoventral in all cows and even craniocaudal in 3 cows. Further, the liver was also seen displaced dorsally along with moderate distention of the gall bladder.

Ultrasonography could not diagnose intestinal intussusceptionin 2 cows with advanced pregnancy. In these cows, the dilated intestinal loops in cross section imaging resembled the placentomesswirling in anechogenic intra-uterine fluid.
Exploratory laparotomy revealed jejuno-jejunal and jejuno-ileal intussusception in 4 and 2 cows, respectively. Intraoperative findings confirmed the telescoping of the alimentary tract along with severe edema of the intestine, particularly of the mesentery which was grossly infiltrated and distended with edematous fluid and noticeably heavy and painful on palpation. The segment of intestine distal to obstruction was collapsed, and proximal segment was greatly distended with ischemic changes. Out of total 6 cases, 4 cows survived and 2 pregnant cows died (Table 2).

\section{Discussion}

Overt signs of the abdominal colic in cattle are manifested only within first 12 hours after the onset of intestinal 
TABLE 2: Summary of clinical cases of intestinal intussusception.

\begin{tabular}{lcccccc}
\hline Bovine & Age (years) & Day of ultrasonography & Day of surgery & POD of surgery & Outcome & Type of intussusception \\
\hline Cow (pregnant) & 5 & 0 & 1 & 6 & Died & Jejunum \\
Cow & 7 & 1 & 2 & 6 & Survived & Jejunum and ileum \\
Cow (pregnant) & 8 & 0 & 1 & 5 & Died & Jejunum \\
Cow & 7 & 0 & 2 & 4 & Survived & Jejunum \\
Heifer & 1.5 & 0 & 0 & 5 & Survived & Jejunum and ileum \\
Heifer & 2 & 1 & 2 & 6 & Survived & Jejunum \\
\hline
\end{tabular}

Day 0: first day of admission and POD: post-operative day.

intussusception and subside with the progression of the lesion, usually characterized by an appearance of placidity and/or recumbency [11]. It occurs due to serious effects on the intestine itself, due to spasm associated with the motility disorder, distension due to the trapped fluid, and by gas production from bacteria. It is this distension, and subsequent activation of nociceptive mechanoreceptors within the intestinal wall that leads to the overt signs of visceral pain. With progressive distension of the intestinal wall, there is occlusion of blood vessels. This impairment of blood supply leads firstly to hyperemia and congestion, and ultimately to ischemic necrosis and cellular death, that is manifested clinically by placidity. Thus, in chronic referral cases, patient history and a thorough clinical examination remain decisive in the management of such cases.

In this study, painful transrectal palpation of the suspected intussuscepted massproved to be an important aid in the initial tentative diagnosis. However, it has been reported that the intussusception is palpable in only a minority of affected adult cattle (23\%), and the distended loops of the small intestine are palpable per rectum in only $50 \%$ of cases with the intussusception [3]. Further, in cattle with severely dilated loops of jejunum, transrectal palpation often reveals no abnormal findings, presumably because the fluid-filled and ingesta-filled intestinal loops sink to the ventral part of the abdomen and out of the examiner's reach [6]. In our opinion, small body size of Indian crossbred cattle may be the enabling factor for better transrectal exploration of the abdomen.

The clinical, hematological and biochemical parameters associated with the intestinal intussusception were similar to the previous findings $[11,12]$. The temperature and respiratory rates are relatively unaffected and the heart rate may be normal or elevated, depending on whether or not blood vessels are occluded, and in infarction of a section of intestine, there are signs of endotoxic shock, including low blood pressure, very rapid heart rate, and muscle weakness and recumbency [11]. Values of hematocrit, blood urea-N, hemoglobin, total plasma proteins and lactate in blood, as well as chloride in rumen content were increased in cattle subjected to experimental intestinal obstruction [12]. Hemo-concentration, a mild left shift and an inverted neutrophil-to-lymphocyte ratio are common in cases of intussusception [11].

As the disease progresses, cattle develop bilateral abdominal distention, due to stenosed forestomach efflux and fluid accumulation in the bowel proximal to the obstruction. This was the reason for abnormal topographic boundaries of the rumen, omasum, abomasum, and liver, as depicted by the ultrasonography.

Among the few reports available in the literature till date, trans-abdominal ultrasonography has been successfully employed ina non-pregnant cow [6] and a calf [8]. Transrectal approach was used in other nonpregnant cow after failing to confirm the condition by transabdominal scanning [7]. The ultrasonographic appearances of intussuscepted segment were reported as "target-like" or "bull's-eye" pattern on transverse imaging $[6,8]$ and "sandwich configuration" on longitudinal imaging [7]. These findings were in agreement with our results. In this study, bringing the intestinal mass towards abdominal wall proved to be a useful technique in improving the quality of ultrasonographic imaging since attenuation of ultrasound waves was alleviated owing to depth of large abdomen in cows.

It is easy to scan the intestinal loops in transverse sections rather than longitudinally during transabdominal ultrasonography, and, therefore, the possibility of visualizing intussuscepted segment as "bull's eye" is more likely. In the present study "bull's eye" appearance was optimally visible in all the 4 cows, whereas "sandwich" pattern could be seen only in 2 cows and that too with difficulty. The presence of dilated multiple loops of intestines in a single scanning area was also a prominent ultrasonographic finding in cases of intestinal intussusception in the present study being in agreement with previous reports $[6,8]$. This happens due to excessive entrapment of fluid and gases as well as ingesta in the lumen of the intestinal segments proximal to the site of the obstruction. However, such findings are not confirmatory to intestinal intussusception as these may be observed in any case of intestinal ileus [6]. Excessive distension of gall bladder as seen in present study is related with prolonged anorexia rather than specific to intestinal intussusception as also reported by Braun [13].

Transrectal examination and ultrasonography were unrewarding in the diagnosis of intestinal intussusception in 2 pregnant cows. It was perhaps due to limited area available for scanning the intestines due to recumbence and occupation of a large portion of abdomen by the fetus. In heavily pregnant cows, the pregnant uterus displaces the intestines away from ventral abdominal wall making it difficult to feel an invaginated intestine transrectally [14]. Moreover, in pregnant cows, the possibility of misinterpretation of imaging in differentiating dilated and static intestinal loops 
from placentomes may arise. This can be avoided by paying attention to the isoechogenic texture devoid of echogenic wall and large diameter of placentomes.

In conclusion, ultrasonography is a useful adjunct in supplementing and substantiating the transrectal findings in bovine intestinal intussusception.

\section{References}

[1] P. Barreau, "Intussusception: diagnosis and treatment," in Proceedings of the 33rd World Small Animal Veterinary Congress, Dublin, Ireland, 2008, (Reprinted in IVIS with the permission of congress organizers).

[2] V. B. Reef and S. M. McGuirk, "Ruminant alimentary diseases," in Large Animal Internal Medicine, B. P. Smith, Ed., p. 694, Mosby, St Louis, Mo, USA, 3rd edition, 2002.

[3] P. D. Constable, G. St Jean, B. L. Hull, D. M. Rings, D. E. Morin, and D. R. Nelson, "Intussusception in cattle: 336 cases (19641993)," Journal of the American Veterinary Medical Association, vol. 210, no. 4, pp. 531-536, 1997.

[4] A. Kumar, Diagnostic and therapeutic studies on intestinal obstruction in calves, Ph.D. thesis, CSK Himachal Pradesh Krishi Vishvavidyalaya, Himachal Pradesh, India, 2006.

[5] D. E. Anderson and J. M. I. Ewoldt, "Intestinal surgery of adult cattle," Veterinary Clinics of North America-Food Animal Practice, vol. 21, no. 1, pp. 133-154, 2005.

[6] U. Braun, O. Marmier, and N. Pusterla, "Ultrasonographic examination of the small intestine of cows with ileus of the duodenum, jejunum or ileum," The Veterinary Record, vol. 137, no. 9, pp. 209-215, 1995.

[7] T. Karapinar and M. Kom, "Transrectal ultrasonographic diagnosis of jejunoileal intussusception in a cow," Irish Veterinary Journal, vol. 60, no. 7, pp. 422-424, 2007.

[8] D. Pravettoni, N. Morandi, M. Rondena et al., "Repeated occurrence of jejuno-jejunal intussusception in a calf," Canadian Veterinary Journal, vol. 50, no. 3, pp. 287-290, 2009.

[9] U. Braun and O. Marmier, "Ultrasonographic examination of the small intestine of cows," Veterinary Record, vol. 136, no. 10, pp. 239-244, 1995.

[10] S. Imran, Ultrasonography of bovine abdominal cavity, M.S. thesis, CSK Himachal Pradesh Krishi Vishvavidyalaya, Himachal Pradesh, India, 2010.

[11] O. M. Radostits, C. C. Gay, D. C. Blood, and K. W. Hinchcliff, "Diseases of the intestines of ruminants," in Veterinary Medicine, a Textbook of the Diseases of Cattle, Horses, Sheep, Pigs and Goats, pp. 379-380, W. B. Saunders, Philadelphia, Pa, USA, 10th edition, 2007.

[12] P. Papadopoulos, D. Raptopoulos, A. Dessiris, G. Tsimopoulos, and N. Roumpies, "Experimental intestinal obstruction in cattle-Part II: changes in blood, urine and rumen content chemistry," Zentralbl Veterinarmed A, vol. 32, no. 4, pp. 276$288,1985$.

[13] U. Braun, "Ultrasound as a decision-making tool in abdominal surgery in cows," Veterinary Clinics of North AmericaFood Animal Practice, vol. 21, no. 1, pp. 33-53, 2005.

[14] G. Dirksen, "Digestive system," in Clinical Examination of Cattle, pp. 184-258, Verlag Paul Parey, Hamburg, Germany, 2nd edition, 1979. 

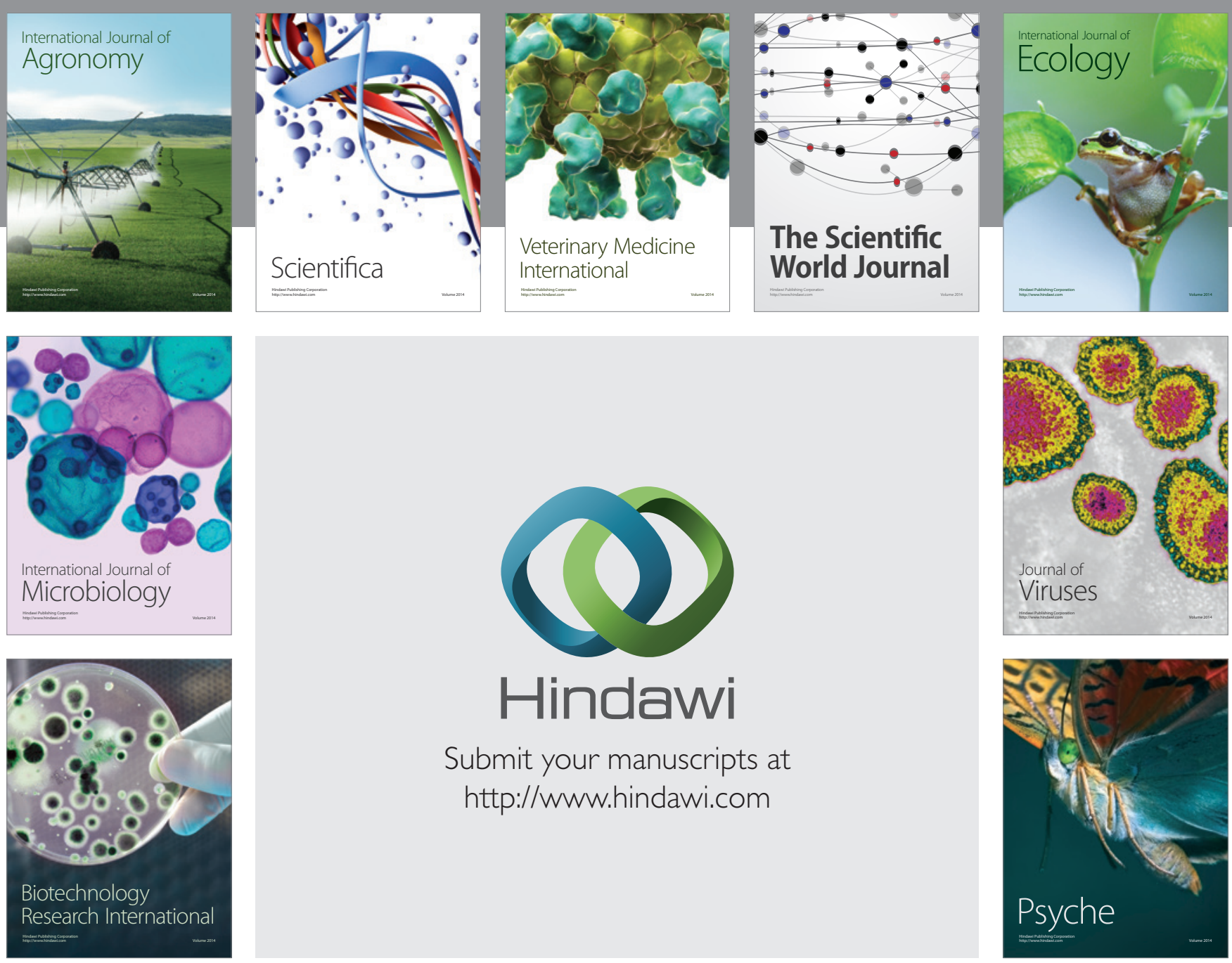

Submit your manuscripts at

http://www.hindawi.com
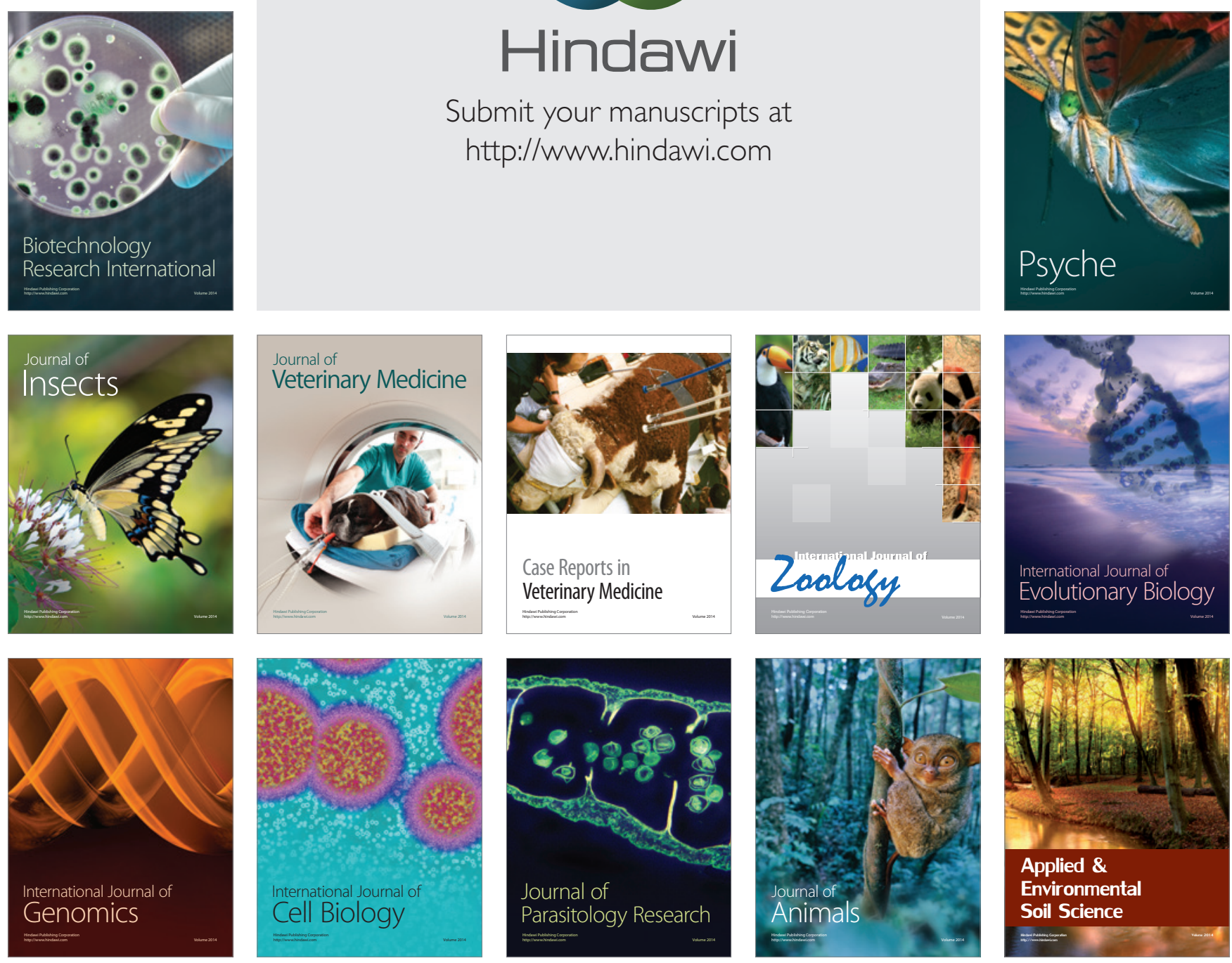